\title{
Sustainable Agricultural Intensification: Evolving Adaptation Fissures and Ecosystem Services Resilience
}

\author{
Nkpeebo A. Yesutanbul ${ }^{1}$, Madyanga P. Juvenary ${ }^{2}$, Nuamah Seth ${ }^{3}$ \\ ${ }^{1}$ Friends of the Earth-Ghana, Forest and Biodiversity Program. Private Mail Bag, GPO, Accra, Ghana \\ 2Dar es Salaam University (DUCE campus), Dar Es Salaam, PO. BOX 2329, Tanzania
}

${ }^{3}$ International Centre for Enterprise and Sustainable Development (ICED), 38 Adjirigano Street, East-Legon, Accra-Ghana

\begin{abstract}
Vulnerable habitats and conditions are becoming fragmented and fragile while species behaviors and disrupting mutualisms of long standing are altering. These challenges represent an extraordinary threat to society and a call for urgent discursive shifts between the scientific community and policy makers. It has been indicated that in order to meet the stated climate change targets, global society will needs to get on board the mitigation train. To date, most of the national climate policy initiatives in developing countries, especially in Sub-Saharan Africa, have focused on adaptation, notably through the National Adaptation Programme of Action. Recent however, climate discourses have indicated the significance of synergies between mitigation and adaptation actions with a shift towards developing climate resilient economies or green growth. Therefore, inSub-Saharan Africa, in order for mitigation train to obtain a moral high ground, we need to question how society is getting onboard the adaptation train. Whereas the emergence of adaptation and mitigation linkages brings to focus new prospects for management of farms, crops, livestock, aquaculture and capture fisheries, the prospects for Climate Smart Agriculture is still riddled with local knowledge and data gaps amidst new data capture and knowledge generation opportunities. In this article we discuss these gaps, highlight one promising climate smart innovation, the Bhungroo Irrigation Technology and the most efficient ways by which rural communities could be engaged. It was determined that multistakeholder dialoguing will better be able to facilitate underlying opportunities or challenges supplanting the broader fixation on techno-infrastructural studies with more socio-technical systems thinking.
\end{abstract}

Keywords: Mitigation Train, Adaptation Train, Climate Smart Agriculture, Bhungroo Irrigation Technology, Multi-Stakeholder Dialoguing

\section{Study Background; Resilience through Mitigation and Adaptation Synergies}

Agriculture remains is a major contributor to climate change, blamable for around a quarter of total anthropogenic GHG emissions (Bogdanski, 2012). At the same time, the recently released fifth assessment report of the Intergovernmental Panel on Climate Change (IPCC) observes that the effects of climate change on crop and food production are already evident in several regions of the world, with negative effects more common than positive ones, and developing countries highly vulnerable to further negative impacts from climate change on agriculture (IPCC, 2014). Non-CO2 emissions from agriculture are projected to increase significantly unless there is radical departure from business-as-usual growth options (Smith, et al., 2014). Climate change, caused mainly by anthropogenic greenhouse gas emissions, is disrupting ecosystem base in new ways. Already, vulnerable habitats and conditions are becoming fragmented and fragile while species behaviors and disrupting mutualisms of long standing are altering. These challenges represent an extraordinary threat to society and a call for urgent discursive shifts between the scientific community and policy makers.

This radical departure will follow the implementation of new practices that enhance the efficiency of input use so that the increase in agricultural output is greater than the increase in emissions (Smith, et al., 2014). To date, most of the national climate policy initiatives in developing countries, especially in Sub-Saharan Africa (SSA), have focused on adaptation, notably through the National Adaptation Programme of Action (NAPAs). Recent climate discourses have however witnessed a shift from National Adaptation Programme of Action (NAPAs) to initiatives that aim to develop climate resilient economies or low-emission development strategies or green growth. The IPCC AR5 observes that research on the linkages between emission reductions and adaptation is still at an early stage and most of the synergies between adaptation and mitigation are centred on the agricultural and forestry sectors. Since climate change alters the functions of ecological systems, the mitigation and adaptation options also have implications for ecosystem services and environmental resilience. Whereas adaptation and mitigation measures and impacts have place premium on agriculture and forestry, little emphasis has been placed on the link to the ecosystem services that people rely on them (IPCC, 2014).

Multiple objective environmental management can generate benefits for food security, development, adaptation to climate change (microclimate), water management, soil protection, agro-biodiversity protection and assist with carbon storage and greenhouse gas emission reduction (Smith, et al., 2014; IPCC, 2014; CCAFS, UNFAO. 2014). It has been observed that regulating ecosystem services such as hydrology or biodiversity, including in the soil, can generate production, adaptation and mitigation co-benefits (Smith, et al., 2014). Climate smart Agriculture (CSA) [The 


\section{International Journal of Science and Research (IJSR) \\ ISSN (Online): 2319-7064 \\ Index Copernicus Value (2013): 6.14 | Impact Factor (2014): 5.611}

concept was first launched by FAO in 2010 in a background paper prepared for the Hague Conference on Agriculture, Food Security and Climate Change in the context of national food security and development goals, to tackle three main objectives: Sustainably increasing food security by increasing agricultural productivity and incomes; Building resilience and adapting to climate change; Developing opportunities for reducing greenhouse gas emissions compared to expected trends. See FAO, ClimateSmart Agriculture Sourcebook. 2013] has thus emerged to encourage the quest for agricultural systems in the context of larger landscapes and ecosystems, so as to better understand the inter-linkages between agricultural production and ecosystem services within and external to agro-ecosystems. In his study on GWS in Kenya, Luwesi (2013) uses a modified DPSIR [DPSIR assessment framework. The latter has been used to describe "Driving forces" that lead to environmental degradation of the catchment ("Impacts") and innovative mechanisms put in place by local stakeholders ("Responses") to curb a complex of causal links resulting from "Pressures" by anthropogenic and natural (or bio-physical) processes leading to subsequent "States" of the catchment degradation. See Kristensen, 2004] framework to furether elaborate the entanglements in CSA knowledge relationships. Here, he establishes the biophysical need of GWS schemes, their socio-political acceptability, and their economic viability and financial sustainability in four (4) major steps: (i) A risk assessment of climate change impact on water resources; (ii) A vulnerability assessment of farmers to water disasters; (iii) A sociopolitical appraisal of GWS schemes' acceptability; and (iv) economic and financial analyses of the feasibility of GWS schemes' investments under conditions of drought and flood (Van Aalst, 2006). At the resent presentation of the WG3 report by the IPCC, it was indicated that in order to meet the stated climate change targets, global society need to get on board the mitigation train. In SSA however, in order for mitigation train to obtain a moral high ground, we need to question how global society is getting onboard the adaptation train.

The concern of this paper is that in SSAs, the ways in which many African farmers are already intensifying their production are economically, socially and ecologically questionable. As the number of smallholder farmers intensify, a cross-cutting question arises: to what extent will this agricultural intensification be sustainable? Preventing such unsustainable agricultural intensification in the near future, requires appropriate technologies that can be applied in the local context to achieve sustainable agricultural intensification (SAI). New technologies will enable farmers to solve not only technical problems for agricultural intensification but also institutional, market-based, and policy-based issues that hamper the creation of a conducive environment and incentives for farmers to unleash their capacities and the potential of their land, where access to water resources is very limited. In fact, it is observed that climate change results in erratic rainfall patterns with a cycle of excess water conditions (flooding) and limited water conditions (drought) in most semi-arid and drylands of Africa (Biplab, 2013). Many farms are flooded and face waterlogging issues, which limit farming activities during the rainy season. Unfortunately, most of these farmers do not have access to viable irrigation schemes, and thus are again limited to crop during the dry season. These are major technicalities impeding sustainable agricultural intensification in peri-urban areas of these semi-arid and drylands of Africa. However, using technologies like the Bhungroo, an Indian based water storage technology (meaning "straw") or the PAVE (a German counterpart of Bhungroo), waterlogged/ flooded farmlands may be freed from excess water conditions during the rainy season, by storing this excess water naturally underground in unsaturated layers of soil, and pumping it for farming during the dry season. Bhungroo irrigation technology comes in with a climate smart socio-technical option through which excess water from farm plots are injected underground in monsoon period with an objective that standing crop of the farmers is saved. It works on injection module. The general design of BIT is based on the hydrogeological structure of candidate sites for BIT (Biplab, 2013). Thus the availability and sufficiency of data on the selected sites is crucial to the design success.

It has been observed that in the next 20 years, increasing the productivity and incomes from smallholder crop, livestock, fishery and forestry production systems will be very crucial to achieving global food security. Most of the world's rural communities are directly or indirectly dependent on agriculture which is provisioned, supported or complemented by ecosystem services (CCAFS, UNFAO, 2014). Thus the lack of emphasis on community roles in ecosystem enhancing agriculture should be of significant concern. Also, what is most "climate-smart" depends strongly on biophysical and socio-economic contexts. Whereas the emergence of adaptation and mitigation linkages brings to focus new prospects for management of farms, crops, livestock, aquaculture and capture fisheries, the prospects for CSA is still riddled with local knowledge and data gaps essential for advancing ecosystem services.

In this article we discuss these linkages, highlight one promising climate smart innovation (the Bhungro Irrigation Technology - BIT) that enhance ecosystem services and the most efficient ways by which rural communities could be engaged. We focus attention on the essential knowledge and data gaps required to bolster the benefits of climate smart options. This paper leans on a multi-level modified participatory appraisal tools and methods that enable rural people to share, analyse and enhance their knowledge on CSA options. Data was collected using an evaluation questionnaires from influencer group dialogue platforms and community level resource user groups. It included 6 influencer group dialogue sessions and 6 community level resource user group discussion for up to 8 and 12 people respectively. These dialogues pooled stakeholders to clarify the micro and macro-level data and knowledge gaps and the changes they are supporting in the broader governance framework for sustainable agricultural intensification. In analysis, the study adopts a mix of qualitative conceptual modeling as a visual descriptions applying factor analysis including Principal Component Analysis (PCA) to establish simple patterns in local knowledge and data capture capacities for enhanced through CSA innovations or options.

\section{Volume 5 Issue 2, February 2016}




\section{International Journal of Science and Research (IJSR) \\ ISSN (Online): 2319-7064}

Index Copernicus Value (2013): 6.14 | Impact Factor (2014): 5.611

\section{Capturing and Sharing Technical Knowledge with Modest Tools}

The study observed that agro-ecological farming systems are very knowledge intensive, and require capacity-building and strong local institutional involvement in capturing accurate, reliable and realtime or near real-time data on the preconditions as well as the performance of CSA options such as the BIT. Even though, data has been highlighted as an essential element of enhancing ecosystem services from BIT, it is not just data that is lacking. A successful deployment and upscalling of BIT in Ghana for instance requires a supporting enabling policy frameworks that may be different from the case of India. For that reason, an assessment methodology needs to be developed to demonstrate under which circumstances (how, where and when) the obtainable data modes could be applied to acquire and share knowledge on climate risk resilience, resource use efficiencies and livelihood advancements from CSA options such as BIT.
This study observed that the modes of data capture and knowledge sharing in local communities have changed significantly. However, there is no single best mode of data capture or knowledge sharing that is best for all. The selected mode depends on prevailing local situations such as: Availability of the data capture mode, initial cost acquisition, operational costs, ease of use for local communities, frequency of use, reliability, delivery time, output quality, availability of supporting services, accessibility of supporting services. Figure 1.1 summarizes the data capture ratings of three local community groups (farmers' association, water user association and women's groups. Table 1.1 to 1.3 presents a detailed data generation capacity of three local community groups (farmers' association, water user association and women's groups). These groups demonstrated quite different data gathering capacities.

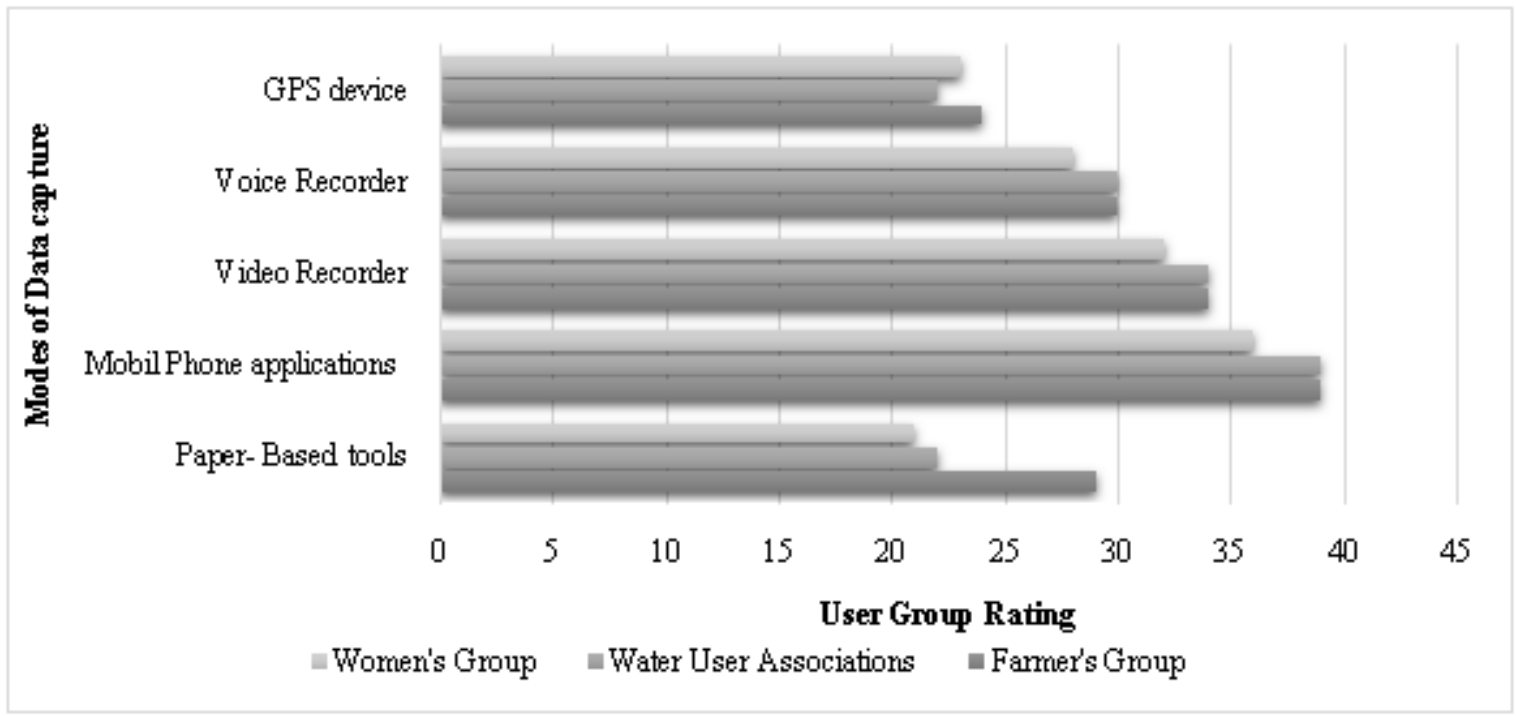

Figure 1.1: Summary of Local Ratings for Available Modes of Data Capture

Source: Authors, 2015

Table 1.1: Rating of Modes of Data Capture by Farmer Associations

\begin{tabular}{|c|c|c|c|c|c|}
\hline \multicolumn{5}{|c|}{ User Rating [Very Poor:1; Poor =2; Quite Good =3; Good =4; Very Good=5] } \\
\hline End User Perceptions & $\begin{array}{c}\text { Paper- Based } \\
\text { tools }\end{array}$ & $\begin{array}{c}\text { Mobil Phone } \\
\text { applications }\end{array}$ & Video Recorder & Voice Recorder & GPS device \\
\hline Initial costs & 4 & 2 & 1 & 2 & 4 \\
\hline Operational costs & 4 & 2 & 1 & 2 & 3 \\
\hline Reliability & 2 & 5 & 5 & 4 & 3 \\
\hline Delivery time & 2 & 5 & 3 & 4 & 3 \\
\hline Output quality & 2 & 4 & 5 & 3 & 2 \\
\hline Supporting service & 2 & 5 & 3 & 2 & 3 \\
\hline Availability & 4 & 4 & 4 & 4 & 2 \\
\hline Accessibility & 4 & 3 & 3 & 3 & 2 \\
\hline Ease of Use & 3 & 4 & 5 & 4 & 1 \\
\hline Frequency of use & 2 & 5 & 4 & 2 & 24 \\
\hline Total & 29 & 39 & 34 & 30 & \\
\hline
\end{tabular}

Source: Authors, 2015 


\section{International Journal of Science and Research (IJSR)}

ISSN (Online): 2319-7064

Index Copernicus Value (2013): 6.14 | Impact Factor (2014): 5.611

Table 1.2: Rating of Modes of Data Capture by Water User Associations

User Rating [Very Poor:1; Poor =2; Quite Good =3; Good =4; Very Good=5]

\begin{tabular}{|c|c|c|c|c|c|}
\hline \multicolumn{6}{|c|}{ User Rating [Very Poor: Poor =2; Quite Good =3; Good =4; Very Good=5] } \\
\hline End User Perceptions & $\begin{array}{c}\text { Paper- Based } \\
\text { tools }\end{array}$ & $\begin{array}{c}\text { Mobil Phone } \\
\text { applications }\end{array}$ & Video Recorder & Voice Recorder & GPS device \\
\hline Initial costs & 4 & 2 & 1 & 2 & 4 \\
\hline Operational costs & 4 & 2 & 1 & 2 & 2 \\
\hline Reliability & 2 & 5 & 5 & 4 & 2 \\
\hline Delivery time & 2 & 5 & 3 & 4 & 2 \\
\hline Output quality & 2 & 4 & 5 & 3 & 2 \\
\hline Supporting service & 2 & 5 & 3 & 4 & 2 \\
\hline Availability & 2 & 4 & 4 & 3 & 2 \\
\hline Accessibility & 2 & 3 & 3 & 4 & 2 \\
\hline Ease of Use & 1 & 4 & 5 & 2 & 2 \\
\hline Frequency of use & 1 & 5 & 4 & 30 & 2 \\
\hline Total & 22 & 39 & 34 & & \\
\hline
\end{tabular}

Source: Authors, 2015

Table 1.3: Rating of Modes of Data Capture by Women's Groups

\begin{tabular}{|c|c|c|c|c|c|}
\hline User Rating [Very Poor:1; Poor =2; Quite Good =3; Good =4; Very Good=5] \\
\hline $\begin{array}{c}\text { End User } \\
\text { Perceptions }\end{array}$ & Paper- Based Tools & $\begin{array}{c}\text { Mobil Phone } \\
\text { Applications }\end{array}$ & Video Recorder & Voice Recorder & GPS Device \\
\hline Initial costs & 4 & 2 & 1 & 2 & 4 \\
\hline Operational costs & 4 & 2 & 1 & 2 & 3 \\
\hline Reliability & 2 & 5 & 5 & 4 & 3 \\
\hline Delivery time & 2 & 5 & 3 & 4 & 3 \\
\hline Output quality & 2 & 4 & 5 & 3 & 2 \\
\hline Supporting service & 1 & 4 & 3 & 2 & 4 \\
\hline Availability & 2 & 3 & 4 & 4 & 1 \\
\hline Accessibility & 2 & 3 & 3 & 3 & 1 \\
\hline Ease of Use & 1 & 3 & 4 & 2 & 1 \\
\hline Frequency of use & 1 & 5 & 3 & 2 & 23 \\
\hline Total & 21 & 36 & 32 & & \\
\hline
\end{tabular}

Source: Authors, 2015

As shown in tables 1.1 to 1.3 above, the end user rating for mobile phone applications in collecting ecosystem-based data is deemed more applicable. Evidently, the increased mobile penetration in Ghana has had a significant effect on the capacity of local communities to support the gathering of data on various ecosystem variables and scenarios offering collaborative solutions based on networks (of people, of ideas, of sensors), enabling new forms of social innovation. It was observed that this capacity could be enhanced by developing communication decision support system built with instant messaging mobile applications like whatsapp. This application has massive popularity and usage even among rural mobile phone users. Creating such a virtual innovation platform could facilitate simple icon-based and image-rich data capturing and real-time or near real-time information sharing on the ecosystem services from climate smart innovations like BIT. It will be supported with coordinated field verification trips to validate data. This data will be used to generate quarterly GIS maps on the scales patterns of ecosystem services from BIT projects. It will contribute to improving decision making speed and facilitate fact-based decision making for private sector organisations, government departments, communities and other external actors.

\section{Addressing the New Knowledge and Data Ownerships in Climate Smart Agriculture}

The existing evidences indicate that in the case of highly context dependent CSA innovations like BIT, expanding the evidence base in different localities is a crucial element for measuring the effects of this innovation on ecosystem resilience and ecosystem services advancement. One of the key pieces of information that agricultural policy makers need, and often lack, are the current and near-future projected effects of climate change in their country, and the implications for the agricultural priorities and programs of the country. Factors such as increasing rainfall variability, delayed onset of the rainy season, and increasing seasonal maximum temperatures, are all examples of climate change impacts that are already being realized and different responses are needed for effective adaptation for each of these (Biplab, 2013 and Osei-Owusu, 2014). Identifying effective adaptation options to maintain and enhance the capacity of agriculture to generate productivity and income increases needed for food security is thus one fundamental objective of the CSA evidence base. The role local communities in gathering data to support the role out of climate smart options thus becomes more essential. Given the requires capacity boost, local communities will be able to collaborate with academia, research centers, policy makers, the media and government departments in generating quality data on various climate phenomena. This collaboration will be useful in developing recommendations on the type of practice or change in agricultural systems needed for climate smart options like BIT.

As the concept of sustainable development includes current and future generations, the impacts of CSA over time also need to be considered. The study confers with the rather broader perspective that in implementing climate smart

\section{Volume 5 Issue 2, February 2016}




\section{International Journal of Science and Research (IJSR) \\ ISSN (Online): 2319-7064 \\ Index Copernicus Value (2013): 6.14 | Impact Factor (2014): 5.611}

adaptation options, landscape approaches and incentives are needed for a coordinated management of various land-based ecosystem services. These approaches may require tradeoffs, which would need to be explicitly quantified and addressed through negotiated solutions among various stakeholders. The scaling up of landscape approaches requires knowledge management and institutional capacity and must be backed up by an enabling policy and market environment. Coordinating sectoral policies is key to aligning the different goals.In determining appropriate siting of BIT, it is imperative to undertake a robust risk and vulnerability assessment of candidate sites. This is domain that is still less understood as far as BIT implementation in Ghana is concerned. Also, a successful implementation of BIT in Ghana will requires the development of supportive policies and plans, as well as coordination across processes and institutions responsible for agriculture, climate change, food security and land use, to avoid contradictions or inconsistencies. This is accomplished through dialogue amongst key stakeholders in a participatory process to build consent in identifying and managing tradeoffs and capturing any synergies across major policy efforts for agriculture and climate change.

In the final analysis, inclusion of resource managers and value-chain participants (farmers associations, water user associations women's groups, etc.), including the private sector is crucial. Setting up Multi-Stakeholder Dialogue (MSD) platforms is supposed to play a vital role in this process. Informal institutions will continue to exist, find a way to improve and/or influence the dynamics of SAI. What is needed therefore is for formal institutional processes and reforms to engage informal institutions more strongly through MSDs in order to make them work better and filling the essential gaps that otherwise would create a local capacity deficit. Cultivating and maintaining a dynamic and integrative interaction process need to become the new orientation of MSD platforms both at the national and local levels. Simple Participatory Decision Support Systems (PDSS) which target specifically the interface between science and practitioners could bring substantial gains as they increasingly provide operational solutions to support policy makers in dealing with the complex problems of the socio-ecosystem at various scales. With the adoption of PDSS, MSD processes will be able to provide a framework for the organization of information and knowledge (multisource spatial and temporal data) and support policy or decision makers in the assessment of plausible management strategies. MSD combined with PDSS will better be able to facilitate underlying opportunities or challenges supplanting the broader fixation on techno-infrastructural studies with socio-technical systems thinking.

\section{References}

[1] Alfonso G.S., (2015). How to promote territorial development through the CSO-LA thematic programme, WORKSHOP on Decentralisation Reforms - Local Governance - Local and Territorial Development Brussels, 13-17 April 2015

[2] Biplab K.P., (2013). Soil water Rejuvenation, Desertification Control \& Agro Productivity
Augmentation, Field experience through Innovation, Ashoka, India.

[3] Bogdanski, A. 2012. "Integrated food-energy systems for climate-smart agriculture." Agriculture and Food Security 1(1): 1-10.

[4] CCAFS, UNFAO. (2014). Climate-Smart Agriculture: What is it? Why is it needed? Rome, Italy: United Nations Food and Agriculture Organisation (UNFAO).

[5] Durand L., and Lazos E. (2008). The Local Perception of Tropical Deforestation and its Relation to Conservation Policies in Los Tuxtlas Biosphere Reserve, Mexico. Human Ecology 36, 383 - 394. doi: 10.1007 / s10745 - 008 - 9172 - 7, ISSN: 0300-7839.

[6] Doyle, J.K.; Ford, D.N. Mental models concepts for system dynamics research. Syst. Dyn. Rev. 1998, 14, 3-

[7] Durand L., and Vázquez L. B. (2011). Biodiversity conservation discourses. A case study on scientists and government authorities in Sierra de Huautla Biosphere Reserve, Mexico. Land Use Policy 28, 76 - 82. doi: 10.1016 / j.landusepol. 2010.04.009, ISSN: 0264-8377.

[8] Friends of the Earth-Ghana (2014). Lake bosomtwe Project Brief, Ghana

[9] Gilg A. (2009). Perceptions about land use. Land Use Policy 26, Supplement 1, 76 - 82. doi: 10.1016 / j.landusepol.2009.08.018, ISSN: 0264-8377.

[10] IPCC, (2014): Summary for policymakers. In: Climate Change 2014: Impacts, Adaptation, and Vulnerability. Part A: Global and Sectoral Aspects. Contribution of Working Group II to the Fifth Assessment Report of the Intergovernmental Panel on Climate Change [Field, C.B., V.R. Barros, D.J. Dokken, K.J. Mach, M.D. Mastrandrea, T.E. Bilir, M. Chatterjee, K.L. Ebi, Y.O. Estrada, R.C. Genova, B. Girma, E.S. Kissel, A.N. Levy, S. MacCracken,P.R. Mastrandrea, and L.L. White (eds.)]. Cambridge University Press, Cambridge, United Kingdom and New York, NY, USA, pp. 1-32.

[11] Leonardo G. Romeo (2005). A Territorial Approach to Local Development; The missing decentralizationdevelopment link? Workshop on Decentralization Reforms, Local Governance, Local and Territorial Development. Local Development International LLC, New York University, Brussels.

[12] Shisanya, C.A, Luwesi C.N., Obando J. A., 2014, Innovative but Not Feasible: Green Water Saving Schemes at the Crossroad in Semi-Arid Lands, Innovative Water Resource Use and Management for Poverty Reduction in Sub-Saharan Africa: An Anthology (OSSREA), pp. 137-172, ISBN: 978-9994455-75-1

[13] Luwesi, CN, Shisanya, CA \& Obando, JA, 2013, Applied Inventory Models for Evaluating Water and Food Security: Approaches and Lessons from Smallholder Farms of Muooni Catchment, Machakos District, Kenya., JAAS - Vol. 1 (2): 37- 45. ISSN: 2311-6730

[14]Holling, C.S.; Gunderson, L.H.; Peterson, G.D. Sustainability and Panarchies. In Panarchy: Understanding Transformations in Human and Ecological Systems; Gunderson, L.H., Holling, C.S., Eds.; Island Press: Washington, DC, USA; London, UK, 2002; pp. 63-102.

[15] Osei-Owusu P. K. (2014). Overview of Bhungroo. Conservation 


\section{International Journal of Science and Research (IJSR) \\ ISSN (Online): 2319-7064}

Index Copernicus Value (2013): 6.14 | Impact Factor (2014): 5.611

http://conservealliance.org/overview-of-bhungroo/\# Accessed on 22/12/2014.

[16] Pimbert, M.P. Institutionalising Participation and People-Centred Processes in Natural Resource Management: Research and Publications Highlights; International Institute for Environment andDevelopment (IIED) and Institute for Development Studies (IDS), University of Sussex: Brighton, UK, 2004.

[17] Primmer E., and H. Karppinen (2010). Professional judgment in non-industrial private forestry: Forester attitudes and social norms influencing biodiversity conservation. Forest Policy and Economics 12, 136 146. doi: 10.1016 / j.forpol. 2009.09.007, ISSN: 13899341.

[18] Smith P., M. R. Ashmore, H. I. J. Black, P. J. Burgess, C. D. Evans, T. A. Quine, A. M. Thomson, K. Hicks, and H. G. Orr (2013a). The role of ecosystems andtheir management in regulating climate, and soil, water and air quality. Journalof Applied Ecology 50, 812 - 829. doi: 10.1111 / 1365 - 2664.12016, ISSN:00218901.

[19] Morrison, M.; Morgan, M.S. Models as Mediating Instruments. In Models as Mediators: Perspective on Natural and Social Sciences; Morgan, M.S., Morrison, M., Eds.; Cambridge University Press: Cambridge, UK, 1999; pp. 10-37.

[20] Pielke, J.R.A. The Role of Models in Prediction for Decision. In Understanding Ecosystems: The Role of Quantitative Models in Observations, Synthesis, and Prediction; Canham, C., Lauenroth, W., Eds.; Princeton University Press: Princeton, NJ, USA, 2003; pp. 113137. 